\title{
ON THE EFFECT OF CURRENT ON WAVE RUN-UP AND WAVE OVERTOPPING
}

\author{
Stefanie Lorke'; Anja Brüning ${ }^{1}$; Jentsje van der Meer ${ }^{2}$, Holger Schüttrumpf ${ }^{1}$, Antje \\ Bornschein ${ }^{3}$; Stefano Gilli ${ }^{3}$; Reinhard Pohl ${ }^{3}$; Miroslav Spano ${ }^{4}$ Jaromír Ríha ${ }^{4}$, Stefan Werk \\ Flemming Schlütter ${ }^{6}$
}

\begin{abstract}
Intention of the project FlowDike-D is to quantify the impacts of current and wind on wave run-up and wave overtopping and to consider these processes in existing design formulae for estuarine, river and sea dikes. Physical model tests were carried out in the shallow water basin at DHI (Hørsholm/Denmark) for two different dike geometries (1:3 and 1:6 sloped dike). The paper introduces the model setup and test programme followed by a short description of the applied instrumentation. The test results for wave run-up and wave overtopping with oblique and non-oblique wave attack, but without current, correspond well with existing formulae from the EurOtop-Manual (2007). The influence of current parallel to the dike combined with different angles of wave attack on wave overtopping and wave run-up has been quantified. A distinction was made between wave attack with and against the current.
\end{abstract}

Keywords: wave run-up, wave overtopping, physical model test, waves, current, dike, EurOtop-Manual

\section{INTRODUCTION}

Different types of structures, like smooth sloped dikes, are built worldwide to protect adjacent areas from river or coastal flooding during high water levels. In estuaries and along the coast the effect of tidal and storm induced current combined with local wind fields can influence the incoming wave parameters at the dike toe. Furthermore, the wave run-up height and the overtopping amount of water are influenced by the named parameters. Better understanding of wave run-up and wave overtopping processes on dikes leads to an improved design of the dike. The lack of knowledge in this research field may result either in too high and expensive flood protection structures or in a higher risk of flooding because of weak designs.

To consider two new aspects - a current parallel and a wind perpendicular to the dike line physical model tests were performed within two test phases in 2009 at DHI in Hørsholm, Denmark. In the first test phase (EU-Hydralab-FlowDike project) a 1:3 sloped dike was investigated, while a 1:6 sloped dike was tested in the second test phase (BMBF-KFKI-FlowDike-D project). The compilation of both test phases, using the results for the 1:3 dike as well as the results for the 1:6 dike, is done within the FlowDike-D-project.

The main intention of these tests was to determine the run-up height and overtopping amount of water depending on current and wind and combining these parameters with different angles of wave attack. Tests were performed using two dike slopes at two different dike heights each. The four resulting dike configurations were exposed to six different wave conditions. Additionally, flow velocities and flow depths have been measured on the dike crests.

\section{EXPERIMENTAL SETUP}

\section{General Configuration}

Figure 1 gives an overall view of the model setup in the $35 \mathrm{~m}$ wide shallow water basin at DHI. The $16 \mathrm{~m}$ wide wave generator is able to create multidirectional wave spectra as well as long-crested waves. The wind generator was installed in front of and above the wave generator to create a wind field with velocities up to $10 \mathrm{~m} / \mathrm{s}$ at the dike crest. The $26 \mathrm{~m}$ long concrete dike was placed opposite of the wave wordgenerator. The dike was divided into two parts with different crest levels. With this setup it was possible to measure the wave overtopping rate for two different freeboard heights.

\footnotetext{
${ }^{1}$ Institute for Hydraulic Engineering and Water Resources Management (IWW), RWTH Aachen University, Mies-vander-Rohe-Strasse 1, 52056 Aachen, Germany; lorke@iww.rwth-aachen.de; anja_bruening@gmx.de; schuettrumpf@iww.rwth-aachen.de

${ }^{2}$ Van der Meer Consulting B.V;. P.O. Box 423, 8440 AK Heerenveen, The Netherlands; jm@vandermeerconsulting.nl

${ }^{3}$ Institute of Hydraulic Engineering and Technical Hydromechanics (IWD), TU Dresden, 01062 Dresden, Germany; antje.bornschein@tu-dresden.de; Stefano.Gill@tu-dresden.de; Reinhard.Pohl@tu-dresden.de

${ }^{4}$ Faculty of Civil Engineering, Brno University of Technology, Veveri 95, 60200 Brno, Czech Republic; spano.m@fce.vutbr.cz; riha.j@fce.vutbr.cz

${ }^{5}$ Leichtweiß-Institute for Hydraulic Engineering and Water Resources (LWI), Department of Hydromechanics and Coastal Engineering, TU Braunschweig, Beethovenstr. 51a, 38106 Braunschweig; Germany; s.werk@tu-bs.de

${ }^{6}$ Danish Hydraulic Institute (DHI), Agern Allé 5, 2970 Hørsholm, Denmark; fls@dhigroup.com
} 
The wave overtopping volume was measured using two overtopping boxes for each dike section. Overtopping was measured by weighing the overtopping water, which enables a wave by wave analysis. A wave run-up board was located beside the overtopping boxes. An intake basin which was filled by a deep well water pump was located upstream of the wave basin (on the left side in Figure 1). At the boundary between the intake basin and the wave basin a flow straightener was installed. This installation ensured a flow direction parallel to the dike and a uniform inflow across the flow crosssection. The outflow of the wave basin was regulated by a weir with an adjustable crest height to enable different current velocities parallel to the dike. In front of the weir a wave absorber made of perforated metal plates was installed to avoid wave reflection.

While testing water was in front and behind the dike. An opening near the inflow (see Figure 1) allowed the overtopped water to flow back and to ensure a constant water depth in front of the dike.

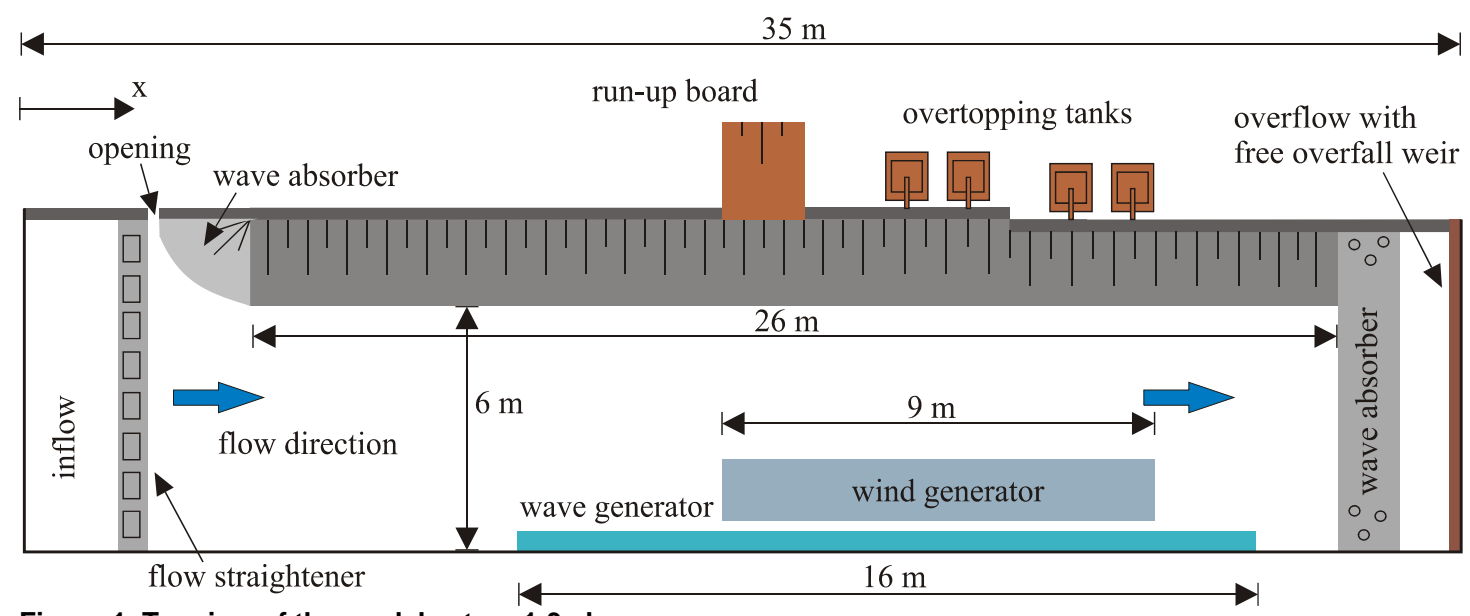

Figure 1. Topview of the model setup, 1:3 slope

\section{TEST PROGRAMME}

The test programme covered model tests with and without current and with and without wind for normal and oblique wave attack. Six different long-crested waves using a Jonswap spectrum were applied. Table 1 presents a summary of the test programme. Normal wave attack is defined with an angle of $\beta=0^{\circ}$. Positive angles of wave attack are in the direction of the current, while negative angles of wave attack are directed against the current.

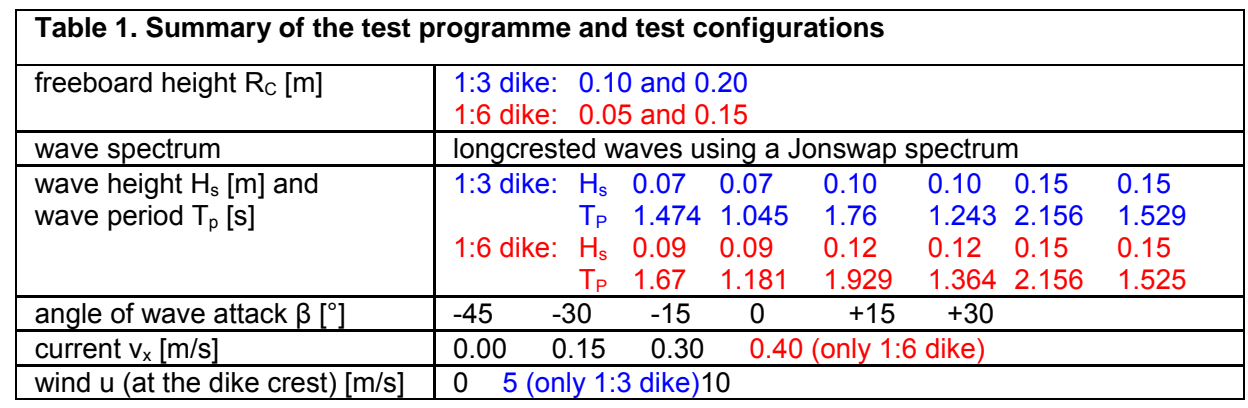

\section{INSTRUMENTATION}

\section{Wave field}

The wave generator created long-crested waves using a Jonswap spectrum. The wave field was measured by two wave arrays of 5 wave gauges and a current meter each. Both wave arrays were located at the dike toe, one for each crest elevation. During the tests with the 1:6 sloped dike an additional wave array was installed directly in front of the wave generator to analyze the evolution of the wave field in the wave basin. The wave arrays were aligned orthogonal between the wave generator and the dike. The sampling rate for all measuring devices was $25 \mathrm{~Hz}$ (1:3 dike) and $40 \mathrm{~Hz}$ (1:6 dike). 


\section{Wave run-up}

A $2 \mathrm{~m}$ wide and $2.5 \mathrm{~m}$ long plywood plate was installed as an extension of the dike slope in order to measure the wave run-up height (see Figure 2). The surface of the plywood plate was covered with sand which was fixed by means of shellac to provide a surface roughness similar to a concrete slope.

Two methods were applied to measure the wave run-up height. First, a capacitive run-up gauge on the run-up-board was used. The capacitive gauge was mounted in the middle of the run-up-plate. Second, a video camera recorded the wave run-up process. Therefore, an adhesive tape with a black/yellow gauge was fixed to the wave run-up plate. The wave run-up board was enlightened by a spotlight to ensure better contrast during the video recordings. The emitted beams of light met the optical axis of the digital cameras within an angle of $120^{\circ}$. For synchronizing all measurements a digital radio controlled clock with a $0.4 \mathrm{~m} \times 0.4 \mathrm{~m}$ display was positioned on the left side of the run-up plate.

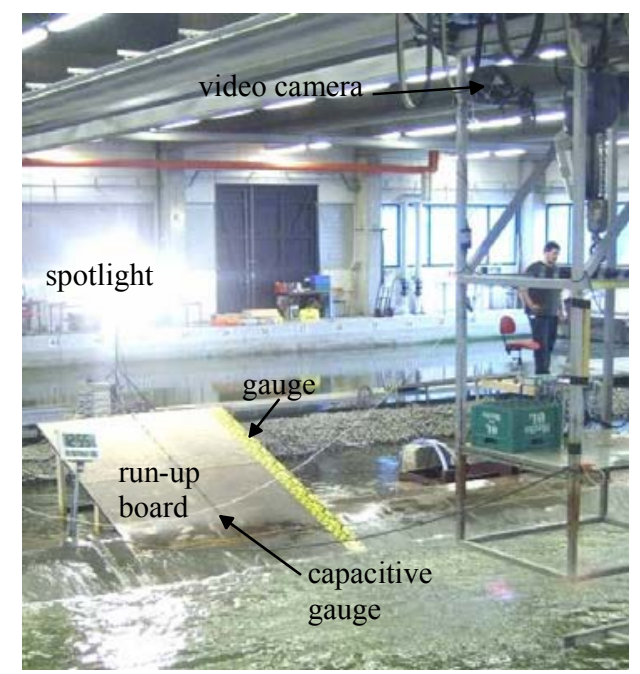

Figure 2. Wave run-up unit, 1:3 dike

\section{Wave overtopping}

The cross-section of an overtopping unit is sketched in Figure 3. On the left hand side the 1:3 sloped dike and the water level in front of the dike is shown. On the right hand side, the overtopping unit has been placed. A $0.1 \mathrm{~m}$ wide overflow channel was connected with the dike crest and led the overtopping water to the inner box of the overflow unit. The inner box had a total volume of $0.66 \mathrm{~m}^{3}$ and was weighed by a pressure cell. Because of the flooded wave basin also behind the dike, it was necessary to place the inner box in a water-tight external box.

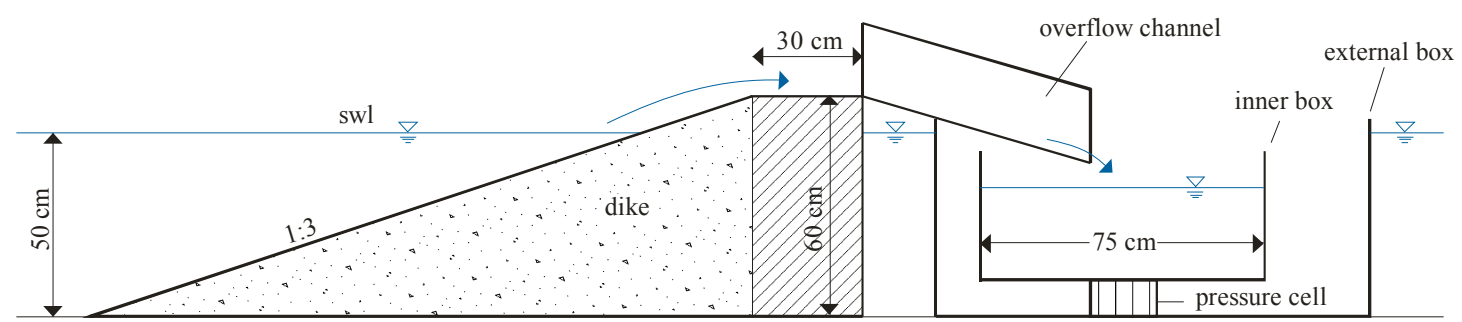

Figure 3. Cross-section of the overtopping unit on the 1:3 sloped dike

One of the four overtopping units (two behind each dike height) is shown in Figure 4. The photo was taken from the rear of the dike. At the photo the water flows from the back crest via the overflow channel into the inner box. Depending on the incoming wave field in front of the dike, the overtopping tanks were sometimes too small to capture the full amount of water for a single test. Then the tanks had to be emptied several times during the test duration of about 30 minutes. Hence, a pump with a predetermined flow was placed in each tank. All pumps (each of them in one of the inner boxes of the four overtopping units) had been connected with the data acquisition system. From the pumping curve and the start and end time of pumping, the lost amount of water could be recalculated to get the whole overtopping volume. An additional pump is located in each external box. 


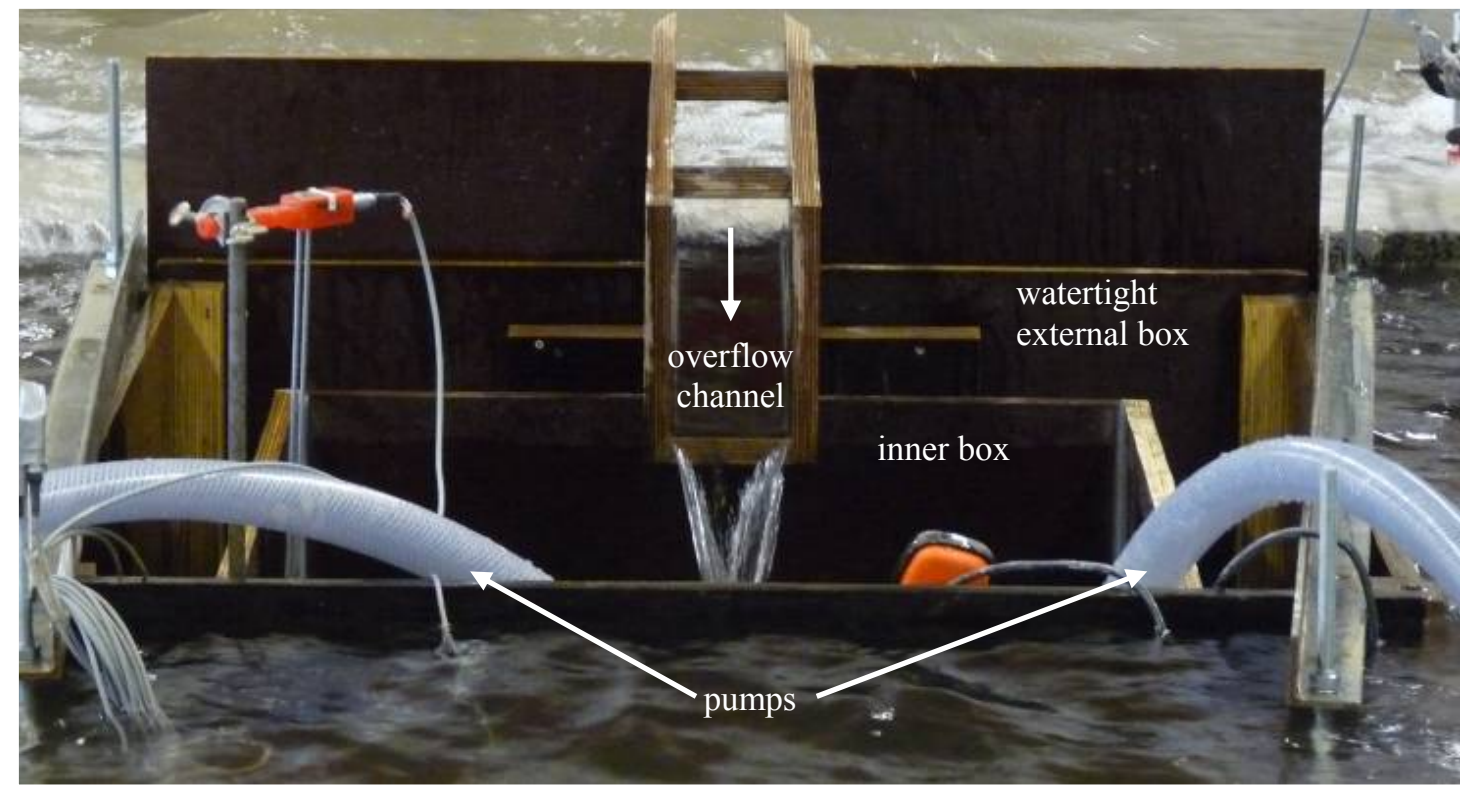

Figure 4. Overtopping unit seen from behind the dike

\section{THEORY - WAVE AND CURRENT INTERACTION}

The model tests were performed with and without a current parallel to the dike. Since the wave propagation is different in flowing water and in still water, it is required to interpret the following results with respect to the interaction of waves and current (Treloar, 1986). Two main aspects have to be considered while interpreting the results:

- current induced shoaling: absolute and relative wave parameters

- current induced wave refraction: energy propagation

The wave propagation path can be divided into two parts. The first part reaches from the wave generator to the dike toe. The second part extends from the dike toe to the dike crest. The first part from the wave generator to the dike toe can be determined using the following formulae for the two aspects:

\section{Absolute and relative wave parameters}

If a wave propagates on a current, a distinction has to be made between relative and absolute wave parameters and can be described by using the wave celerity. The relative wave celerity is the celerity relative to an observer who moves with the current, while the absolute celerity is defined as the velocity compared to a stationary observer and the ground, respectively.

The wave arrays in front of the dike measured the wave field with its absolute parameters. According to Hedges (1987), Treloar (1986) and Holthuijsen (2007) waves act only with its relative parameters. To determine the relative wave period $\mathrm{T}_{\text {rel, } \mathrm{m}-1,0}$ from the measured absolute wave period $\mathrm{T}_{\mathrm{abs}, \mathrm{m}-1,0}$, the absolute angular frequency $\omega_{\mathrm{abs}}$ has to be equalized to the sum of the relative angular frequency $\omega_{\text {rel }}$ and the corresponding constituent of the current $\left(k \cdot v_{n}\right)(\mathrm{cf}$. Holthuijsen, 2007):

$$
\omega_{\mathrm{abs}}=\omega_{\mathrm{rel}}+\mathrm{k} \cdot \mathrm{v}_{\mathrm{n}}=\sqrt{\mathrm{gk} \cdot \tanh (\mathrm{k} \cdot \mathrm{d})}+\mathrm{k} \cdot \mathrm{v}_{\mathrm{n}}
$$

with

$\omega_{\text {abs }}$ absolute angular frequency $[\mathrm{rad} / \mathrm{s}]$

$\omega_{\text {rel }}$ relative angular frequency $[\mathrm{rad} / \mathrm{s}]$

$\mathrm{k} \quad$ wave number $[\mathrm{rad} / \mathrm{m}]$

$\mathrm{V}_{\mathrm{n}} \quad$ current velocity in the direction of wave propagation $[\mathrm{m} / \mathrm{s}]$

d flow depth [m]

The absolute angular frequency is defined as:

$$
\omega_{\mathrm{abs}}=\frac{2 \pi}{\mathrm{T}_{\mathrm{abs}, \mathrm{m}-1,0}}
$$


with the absolute spectral period $\mathrm{T}_{\mathrm{abs}, \mathrm{m}-1,0}$ (EurOtop 2007)

$$
\mathrm{T}_{\mathrm{abs}, \mathrm{m}-1,0}=\frac{\mathrm{T}_{\mathrm{P}}}{1.1}
$$

with $\mathrm{T}_{\mathrm{P}} \quad$ spectral peak period $[\mathrm{s}]$

By using eq. (1) and (2), the wave number $\mathrm{k}$ can be determined iteratively by using the measured absolute wave period $\mathrm{T}_{\mathrm{abs}, \mathrm{m}-1,0}$, the known flow depth $\mathrm{d}$ and the current velocity in the direction of wave propagation $\mathrm{v}_{\mathrm{n}}(\mathrm{cf}$. Figure 5):

$$
\mathrm{v}_{\mathrm{n}}=\mathrm{v}_{\mathrm{x}} \cdot \sin \beta
$$

with the current velocity parallel to the dike $\mathrm{v}_{\mathrm{x}}$ and the angle of wave attack relative to the normal of the dike $\beta$.

The relative angular frequency $\omega_{\text {rel }}$ results in

$$
\omega_{\text {rel }}=\sqrt{\mathrm{g} \cdot \mathrm{k} \cdot \tanh (\mathrm{k} \cdot \mathrm{d})}
$$

and leads to the relative wave period $\mathrm{T}_{\text {rel, } \mathrm{m}-1,0}$ :

$$
\mathrm{T}_{\mathrm{rel}, \mathrm{m}-1,0}=\frac{2 \pi}{\omega_{\text {rel }}}
$$

The relative wave period $\mathrm{T}_{\text {rel, } \mathrm{m}-1,0}$ decreases when the wave propagates against the current and increases by wave propagation with the current (cf. formula (1) and (4)).

\section{Angle of wave energy}

Figure 5 shows schematically the combination of the two vectors for the current and the wave direction for negative (left) and positive (right) angles of wave attack. The dashed arrow describes the relative direction of the wave attack generated by the wave generator and the corresponding angle $\beta$. The dotted arrow indicates the direction of the current parallel to the dike. According to Holthuijsen (2007) the current does not change the angle of wave attack but its energy direction by the combination of the two vectors current velocity $\mathrm{v}_{\mathrm{x}}$ and relative group velocity $\mathrm{c}_{\mathrm{g}, \mathrm{rel}}$ marked with the corresponding arrow. As shown in Figure 5, negative angles of wave attack lead to a smaller absolute value of the angle of wave energy $\beta_{\mathrm{e}}$ whereas positive angles of wave attack lead to a higher angle of wave energy $\beta_{\mathrm{e}}$ than the angle of wave attack $\beta$.

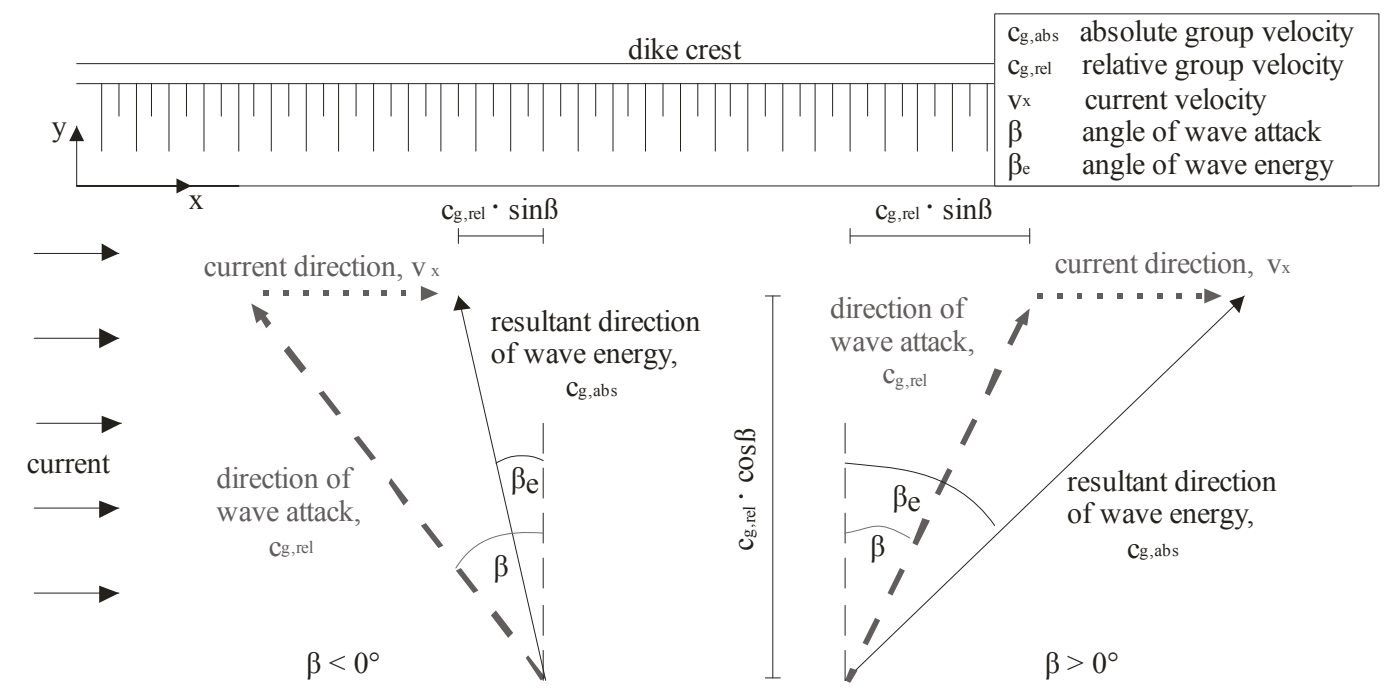

Figure 5. Interaction between wave direction and current

With the help of Figure 5 the angle of wave energy $\beta_{\mathrm{e}}$ is determined by the relative group velocity $c_{g, r e l}$, the angle of wave attack $\beta$ and the current velocity $v_{x}$ by the trigonometrical function:

$$
\tan \beta_{\mathrm{e}}=\frac{\mathrm{c}_{\mathrm{g}, \mathrm{rel}} \cdot \sin \beta+\mathrm{v}_{\mathrm{x}}}{\mathrm{c}_{\mathrm{g}, \mathrm{rel}} \cdot \cos \beta}
$$


Herein the relative group velocity $c_{g, r e l}$ is determined by the following formula:

$$
\mathrm{c}_{\mathrm{g}, \mathrm{rel}}=\frac{\partial \omega}{\partial \mathrm{k}}=\frac{\partial(\sqrt{\mathrm{g} \cdot \mathrm{k} \cdot \tanh (\mathrm{k} \cdot \mathrm{d})})}{\partial \mathrm{k}}
$$

which leads to:

$$
\mathrm{c}_{\mathrm{g}, \text { rel }}=0.5 \cdot \frac{\omega_{\text {rel }}}{\mathrm{k}}\left(1+\frac{2 \cdot \mathrm{k} \cdot \mathrm{d}}{\sinh (2 \cdot \mathrm{k} \cdot \mathrm{d})}\right)
$$

\section{METHOD OF ANALYSIS}

The EurOtop-Manual (2007) has been used to analyse the data and to derive influencing factors including current. The EurOtop-Manual (2007) distinguishes between formulae for wave run-up and wave overtopping, for breaking and non-breaking wave conditions.

\section{Wave run-up}

Usually the influence of different factors on wave run-up height could be determined using a formula which was originally suggested by Hunt (1959) and than upgraded in EurOtop-Manual (2007) with different correction parameters:

$$
\frac{\mathrm{R}_{\mathrm{u} 2 \%}}{\mathrm{H}_{\mathrm{m} 0}}=\mathrm{c}_{1} \cdot \gamma_{\mathrm{b}} \cdot \gamma_{\mathrm{f}} \cdot \gamma_{\beta} \cdot \xi_{\mathrm{m}-1,0}
$$

with its maximum:

$$
\frac{\mathrm{R}_{\mathrm{u} 2 \%}}{\mathrm{H}_{\mathrm{m} 0}}=\gamma_{\mathrm{f}} \cdot \gamma_{\beta} \cdot\left(\mathrm{c}_{2}-\frac{\mathrm{c}_{3}}{\sqrt{\xi_{\mathrm{m}-1,0}}}\right)
$$

with

$\mathrm{R}_{\mathrm{u} 2 \%}$ wave run-up height which will be exceeded by $2 \%$ of all wave run-ups [m]

$\gamma_{\mathrm{b}} \quad$ parameter which covers the influence of a berm [-]

$\gamma_{\mathrm{f}} \quad$ parameter which covers the influence of surface roughness [-]

$\gamma_{\beta} \quad$ parameter which covers the influence of wave direction (angle $\beta$ ) [-]

$\xi_{\mathrm{m}-1,0}$ breaker parameter based on $\mathrm{s}_{\mathrm{m}-1,0}[-]$

$\mathrm{s}_{\mathrm{m}-1,0}$ wave steepness based on $\mathrm{H}_{\mathrm{m} 0}$ and $\mathrm{L}_{\mathrm{m}-1,0}[-]$

$\mathrm{L}_{\mathrm{m}-1,0}$ deep water wave length based on $\mathrm{T}_{\mathrm{m}-1,0}[\mathrm{~m}]$

$\mathrm{T}_{\mathrm{m}-1,0}$ spectral wave period [s]

$\mathrm{H}_{\mathrm{m} 0} \quad$ significant wave height from spectral analysis [m]

The empirical parameters $\mathrm{c}_{1}, \mathrm{c}_{2}$ and $\mathrm{c}_{3}$ are dimensionless and defined as follow:

$$
\mathrm{c}_{2}=\mathrm{c}_{1} \cdot \xi_{\mathrm{tr}}+\mathrm{c}_{3} / \xi_{\mathrm{tr}}
$$

with

$\xi_{\text {tr }} \quad$ surf parameter describing the transition between breaking and non breaking waves [-]

For a prediction of the average run-up height $\mathrm{R}_{\mathrm{u} 2 \%}$ the following values $\mathrm{c}_{1}=1.65, \mathrm{c}_{2}=4.0$ and $\mathrm{c}_{3}=1.5$ should be used.

\section{Wave overtopping}

Formulae (13) can be used to calculate the average overtopping discharge q per meter dike length for given geometry and wave condition. As the non breaking condition the overtopping discharge limits to a maximum value, see formula (14). The smallest value of both equations should be taken as the result. 
Breaking wave conditions:

$$
\frac{\mathrm{q}}{\sqrt{\mathrm{g} \cdot \mathrm{H}_{\mathrm{m} 0}^{3}}}=\frac{0.067}{\sqrt{\tan \alpha}} \cdot \gamma_{\mathrm{b}} \cdot \xi_{\mathrm{m}-1,0} \cdot \exp \left(-4.75 \frac{\mathrm{R}_{\mathrm{C}}}{\xi_{\mathrm{m}-1,0} \cdot \mathrm{H}_{\mathrm{m} 0} \cdot \gamma_{\mathrm{b}} \cdot \gamma_{\mathrm{f}} \cdot \gamma_{\beta} \cdot \gamma_{\mathrm{v}}}\right)
$$

With a maximum for non breaking wave conditions:

$$
\frac{\mathrm{q}}{\sqrt{\mathrm{g} \cdot \mathrm{H}_{\mathrm{m} 0}^{3}}}=0.2 \cdot \exp \left(-2.6 \frac{\mathrm{R}_{\mathrm{C}}}{\mathrm{H}_{\mathrm{m} 0} \cdot \gamma_{\mathrm{f}} \cdot \gamma_{\beta}}\right)
$$

with

q mean overtopping discharge per meter structure width $\left[\mathrm{m}^{3} / \mathrm{s} / \mathrm{m}\right]$

$\alpha \quad$ slope of the front face of the structure $\left[{ }^{\circ}\right]$

$\mathrm{R}_{\mathrm{c}} \quad$ crest freeboard of structure [m]

$\gamma_{v} \quad$ correction factor for a vertical wall on the slope [-]

Furthermore, reduction factors for wave overtopping for obliqueness $\gamma_{\beta}$ can be determined by comparing the exponential coefficients $b_{\beta}$ for oblique wave attack $(\beta \neq 0)$ and normal wave attack $(\beta=0)$ :

$$
\gamma_{\beta}=\frac{b_{\beta=0}}{b_{\beta}}
$$

A new reduction factor $\gamma_{\beta, \text { cu }}$ is introduced in the same way to take the influence of current $\mathrm{v}_{\mathrm{x}}$ into account:

$$
\gamma_{\beta, \mathrm{cu}}=\frac{\mathrm{b}_{\beta=0, \mathrm{cu}=0}}{\mathrm{~b}_{\beta, \mathrm{cu}}}
$$

\section{FIRST RESULTS}

\section{Definitions and Remarks}

- Reference tests are defined as tests with perpendicular wave attack, without current and without wind but with different wave parameters.

- Normal wave attack is equivalent to a wave angle of $\beta=0^{\circ}$.

- Wave attack along with the current is described by positive angles of wave attack, whereas wave attack against the current gives negative angles.

- The 1:3 sloped dike was analyzed for breaking and non breaking waves, while the 1:6 sloped dike was investigated only for breaking waves, as for such a gentle slope only breaking conditions were present.

- Changes of wave heights due to current are measured by the wave gauges at the toe of the dike.

Wave run-up

To validate the overall model setup, results from reference tests (1:3 dike as well as 1:6 dike) are compared to data of former investigations. Figure 6 shows calculated values of relative wave run-up height $\mathrm{R}_{\mathrm{u} 2 \%} / \mathrm{H}_{\mathrm{m} 0}$ versus breaker parameter $\xi_{\mathrm{m}-1,0}$. Several functions of former investigations have been added to the figure including equation (10) and (11) by EurOtop-Manual (2007). Values for $\mathrm{H}_{\mathrm{m} 0}$ were obtained analysing measurement results of the wave array which was situated closer to the run-up plate. Values for wave run-up height were measured by the capacitive gauge.

Relative wave run-up of reference model test is little lower than expected by EurOtop 2007. This is explicable because the function of EurOtop-Manual (2007) is only valid for smooth dike slopes. The rougher surface of the dike slope in the model setup causes slightly lower wave run-up heights. Breaker parameter $\xi_{\mathrm{m}-1,0}$ is greater than 0.8 for 1:6 dike model tests and greater than 1.5 for the 1:3 dike model tests. 


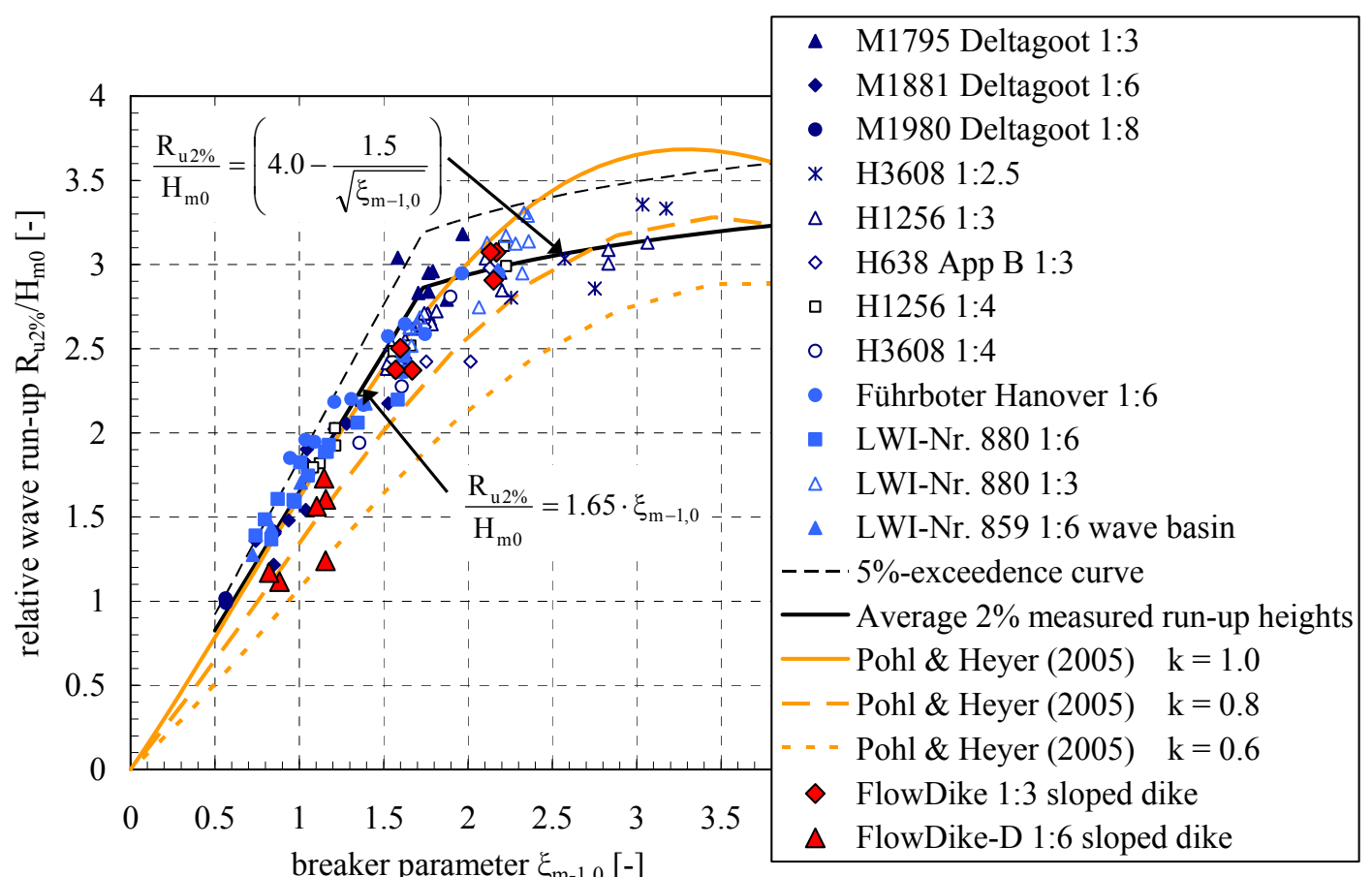

Figure 6. Relative wave run-up height $\mathbf{R}_{\mathrm{u} 2 \%} / \mathrm{H}_{\mathrm{m} 0}$ versus breaker parameter $\xi_{\mathrm{m}-1,0}$ - comparison between reference tests and former investigations from the EurOtop-Manual (2007)

It was expected that the wave run-up considering oblique wave attack is lower than wave run-up with orthogonal wave direction. In addition decreasing wave run-up height because of a dike parallel current was anticipated. In order to determine an average reduction factor $\gamma_{\beta}$ as the ratio between relative run-up heights of model tests with oblique wave attack, current and/or wind against relative run-up height of the reference test linear regression was used as one can see in Figure 7. The factor $\gamma_{\beta}$ is equal to the slope of the regression line.

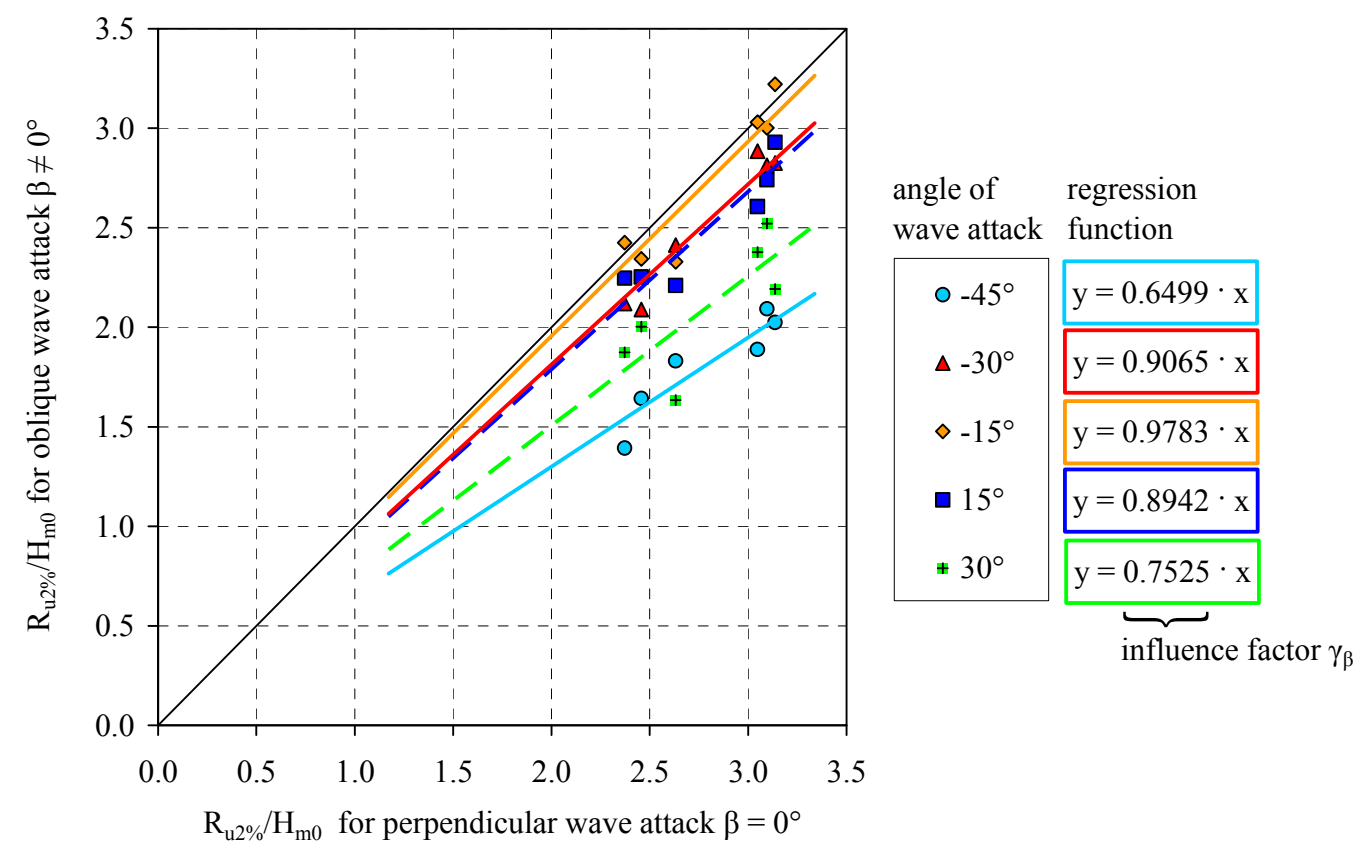

Figure 7. Relative wave run-up height: comparison between reference tests $(\beta=0)$ and model tests with oblique wave attack (current velocity $v_{x}=0.15 \mathrm{~m} / \mathrm{s}$ ) 
The reduction factors of measurement analysis analogue to Figure 7 are expected to be dependent of the angle of wave attack. This is presented in Figure 8 together with some empirical functions (Oumeraci et al., 2001). It must be pointed out that the older functions were developed for wave run-up without current. On the one hand the formula of Wagner \& Bürger (1973) agrees to the own results for smaller values of $\beta$. On the other hand the bigger the angle of wave attack the bigger the discrepancy to the values on the basis of measurements. These factors correspond to the formula given by De Waal and Van der Meer (1992):

$$
\begin{array}{cc}
\text { for } \beta<-10^{\circ} \text { and } \beta>10^{\circ} & \gamma_{\beta}=\cos ^{2}(|\beta|-10) \\
\text { for }-10^{\circ}<\beta>10^{\circ} & \gamma_{\beta}=1
\end{array}
$$

The de Waal \& Van der Meer formula refers only to the test results without current and is valid for $\beta \leq 40$ considering the model tests.

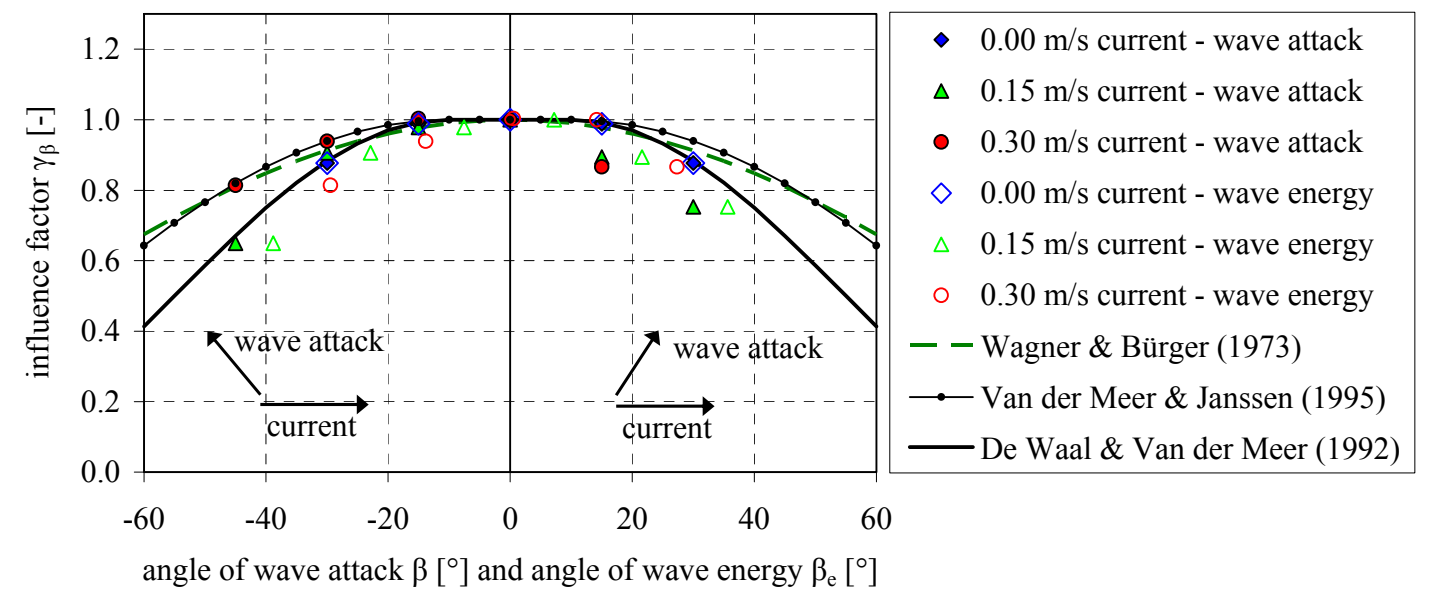

Figure 8. Factor $\gamma_{\beta}$ versus angle of wave attack $\beta$ and angle of wave energy $\beta_{\mathrm{e}}$ : test results and empirical functions, wave run-up, 1:3 sloped dike

In applying the influence of dike parallel current on the 1:3 sloped dike by using the angle of wave energy $\beta_{\mathrm{e}}$ (formula (7)) instead of the angle of wave attack $\beta$ the formulae (17) and (18) show a good agreement with results of tests with a dike parallel current too. This confirms the approach to include the influence of dike parallel current considering its effects on characteristics of incoming waves.

\section{Wave overtopping}

\section{Reference tests}

Figure 9 shows the results of the reference tests for the 1:3 and 1:6 sloped dikes for breaking waves. In Figure 10 the regression curve for non-breaking waves for the 1:3 dike is given. All regression lines of the two dike slopes (dotted graph (1:3 dike) and dashed graph (1:6 dike)) are slightly lower than the recommended formula of the EurOtop-Manual (2007), but still lying within the confidence interval of $5 \%$. In the following analysis the inclination of the graph of the corresponding reference test is used to determine the influence factors $\gamma_{\mathrm{i}}$ for the three different conditions:

- 1:3 dike for breaking wave conditions

- $\quad 1: 3$ dike for non-breaking wave conditions

- 1:6 dike for breaking wave conditions 


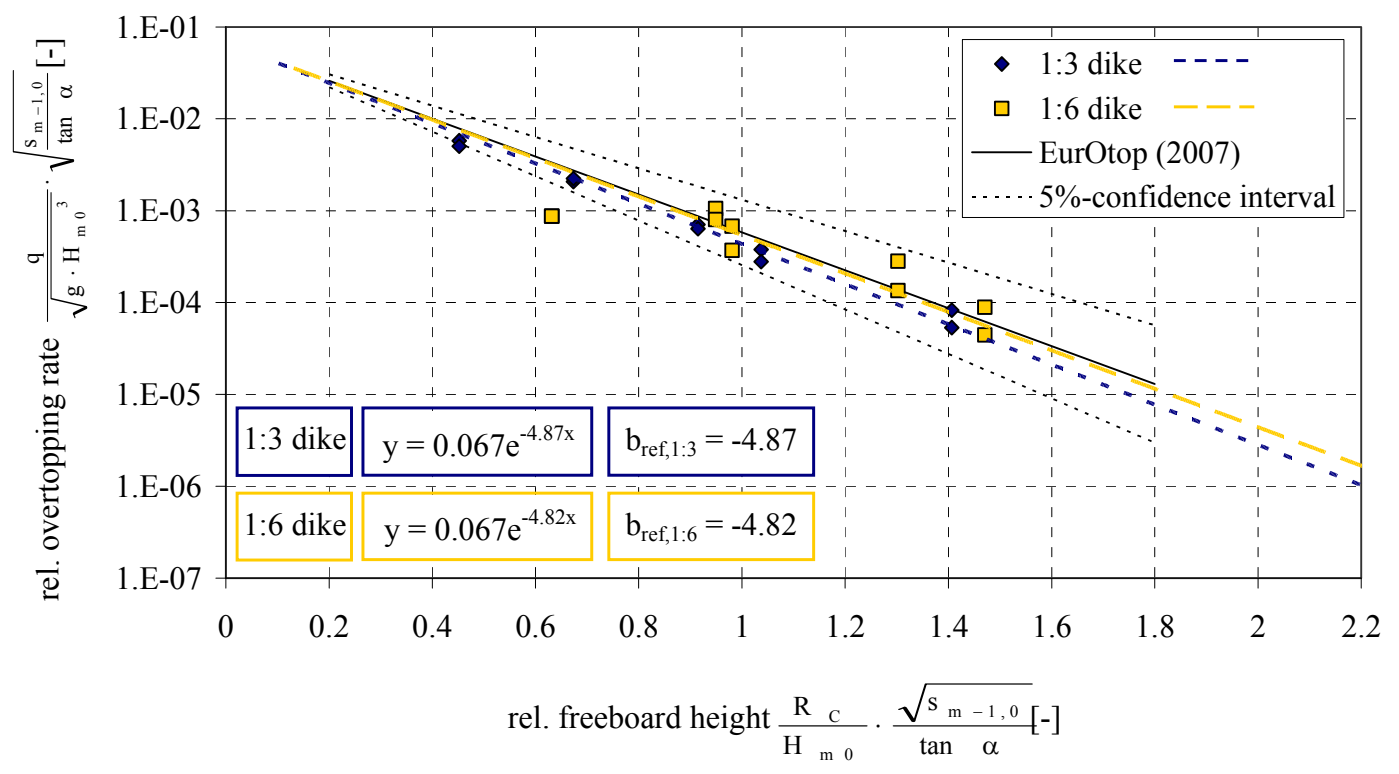

Figure 9. Relative overtopping rate - reference tests for breaking wave conditions (1:3 dike, 1:6 dike)

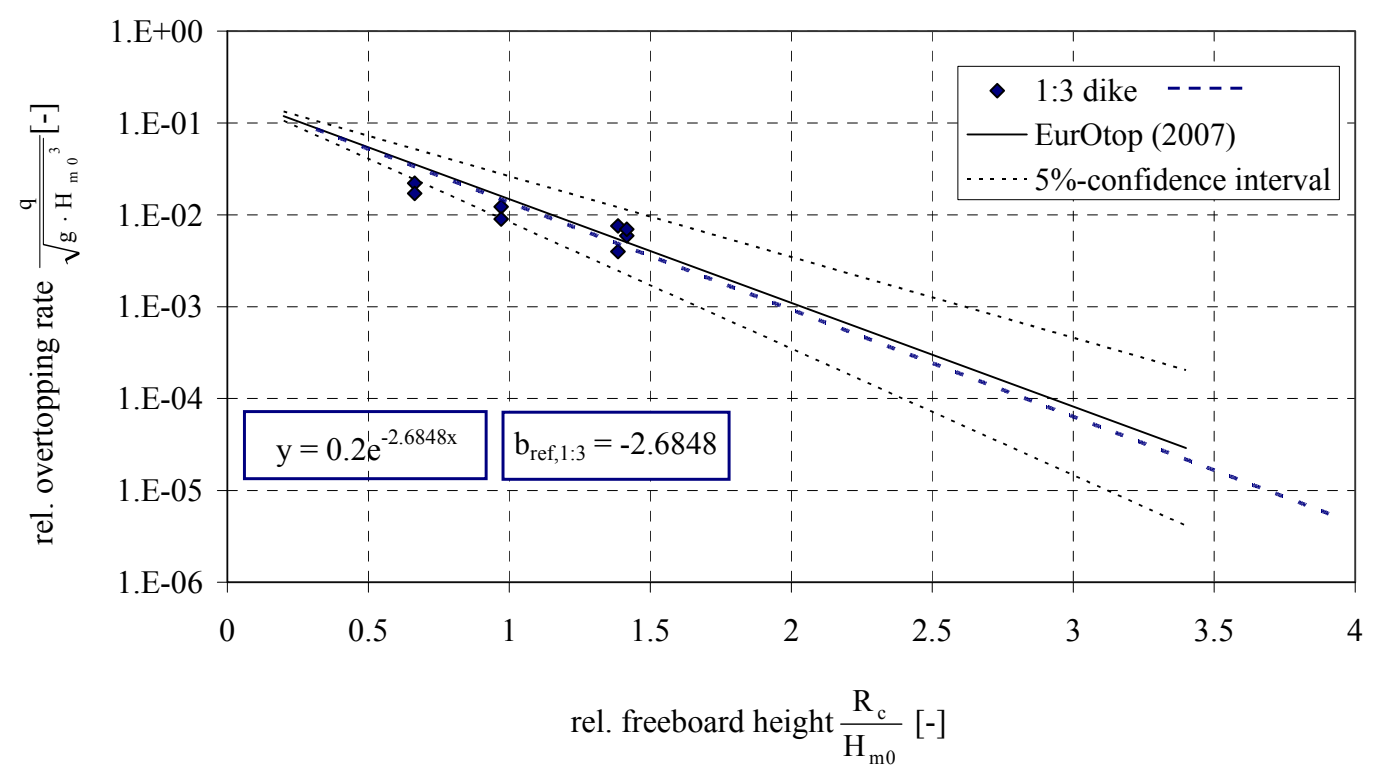

Figure 10. Relative overtopping rate - reference test for non-breaking wave conditions (1:3 dike)

The following paragraphs describe the analysis of the different influencing factors $\gamma_{\beta}$ and $\gamma_{\beta, c u}$ (see formulae (15) to (16)) implicating the theory described above.

\section{Oblique wave attack}

Previous investigations by Wassing (1957), Tautenhain (1982), Oumeraci et al. (2001) and De Waal and van der Meer (1992) resulted in different formulae for the reduction factor $\gamma_{\beta}$. The De Waal \& Van der Meer formula was selected due to the availability of recent and comprehensive data. Moreover, it was used for comparison purposes in the present study. In Figure 11 the angle of wave attack is given on the x-axis. The corresponding influence factors $\gamma_{\beta}$ for the different angles of wave attack are given on the $y$-axis. The graph shows the recommended line from the EurOtop-Manual (2007). The influence factors $\gamma_{\beta}$ of the 1:3 and the 1:6 sloped dike are shown by the diamond shaped and quadrat data points, respectively. These factors correspond to the formula given by De Waal and Van der Meer (1992) above (formulae (17) and (18)). The reduction factors for the 1:3 dike are a little bit lower than for the 1:6 dike. This can be explained by a slightly higher refraction of the waves between the dike toe and the point of wave breaking for the 1:6 dike (cf. Ohle et al., 2002). 


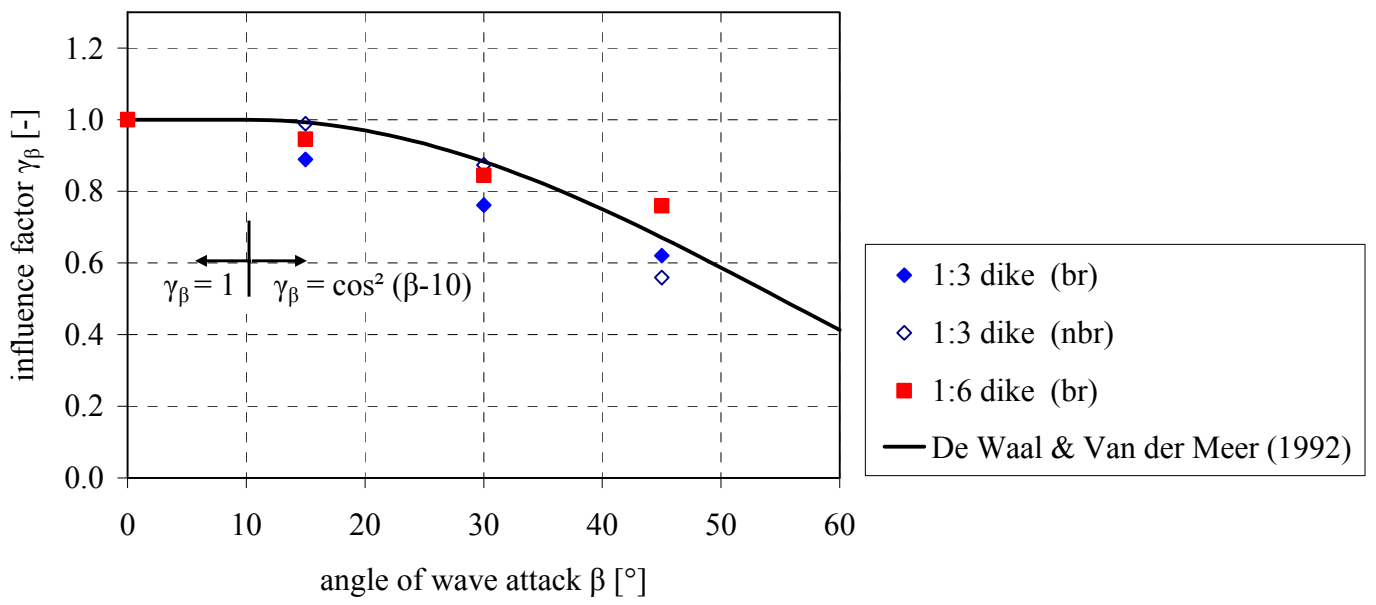

Figure 11. Influence of angle of wave attack on wave overtopping

\section{Combination oblique wave attack and current}

In a first step, a characteristic factor was applied to determine the influence of a combination of oblique waves and current parallel to the dike structure. The absolute wave parameters are used. A distinction was made between the results for the 1:3 sloped dike for breaking and non breaking waves (see Figure 12 and Figure 13) and the results for the breaking waves on the 1:6 sloped dike (see Figure 14). The diamonds show the influence factors for tests without current. An increase of the influence factor for increasing current velocity, shown by the triangles $(0.15 \mathrm{~m} / \mathrm{s})$, circles $(0.30 \mathrm{~m} / \mathrm{s})$ and squares $\left(0.40 \mathrm{~m} / \mathrm{s}\right.$ only $1: 6$ dike), is noticeable except for the $-15^{\circ}$ and $30^{\circ}$ tests for non-breaking waves (1:3 dike) and for the $30^{\circ}$ test for breaking waves (1:6 dike). For normal wave attack the 1:3 dike for breaking wave conditions a decrease of the influence factor and consequently an increasing wave overtopping rate is noticeable for increasing current velocities.

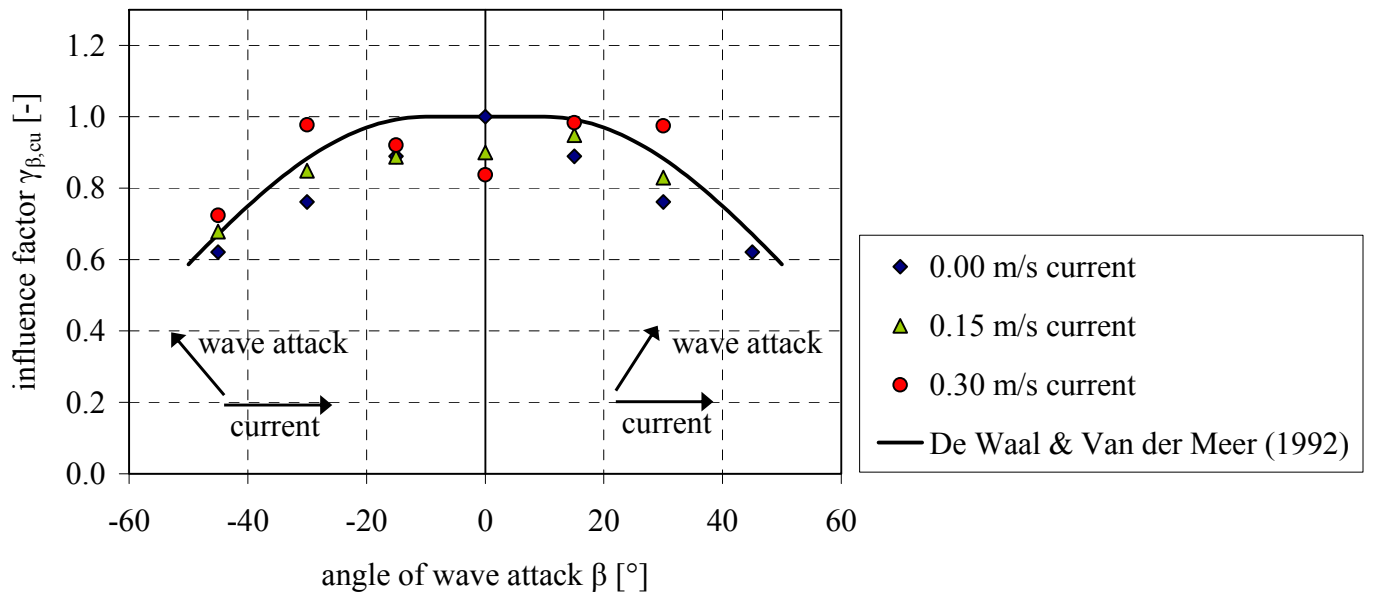

Figure 12. Current influence on wave overtopping, 1:3 dike, breaking waves 


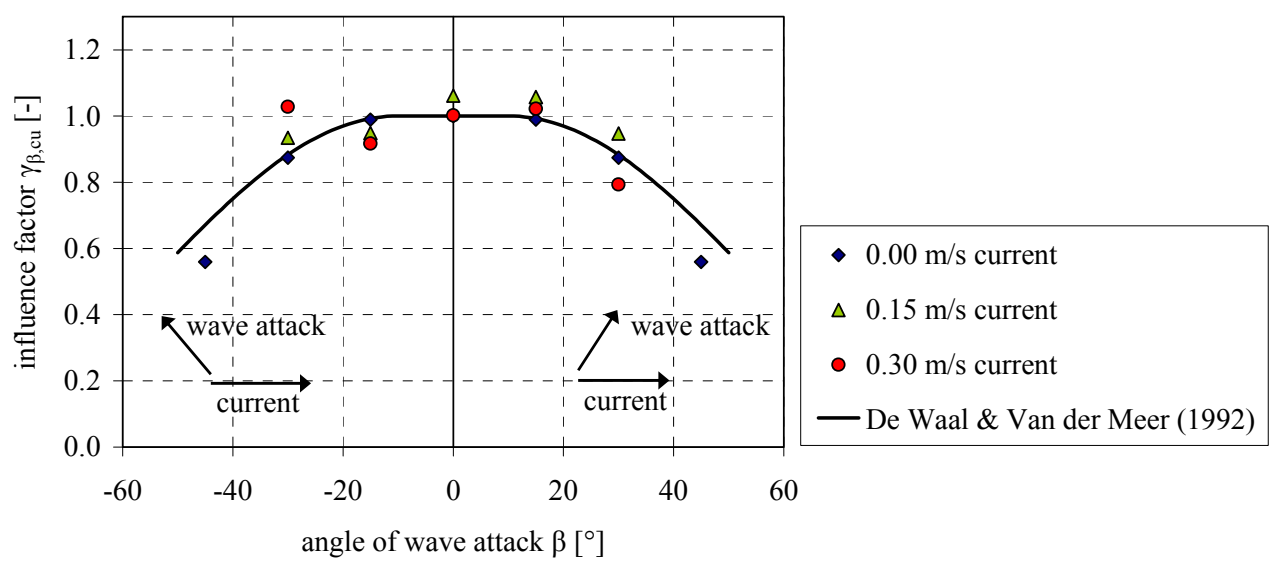

Figure 13. Current influence on wave overtopping, 1:3 dike, non breaking waves

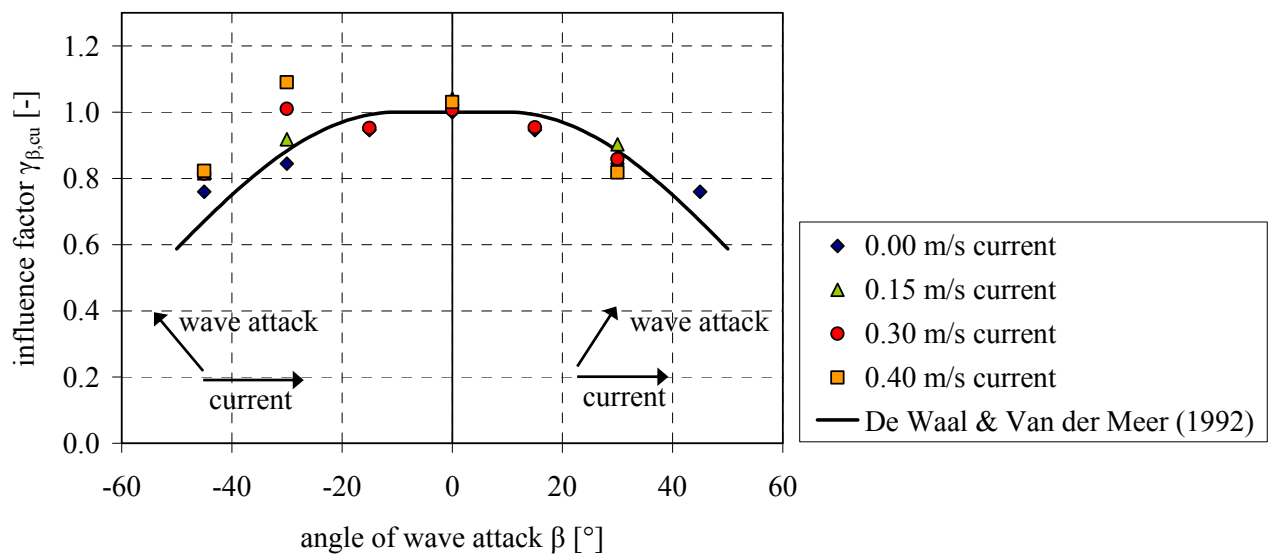

Figure 14. Current influence on wave overtopping, 1:6 dike, breaking waves

For non-breaking waves the relative overtopping rate and the relative freeboard height is determined independent of the wave period (cf. Figure 9 and 10). Hence using the relative wave period only changes the influence factor $\gamma_{\beta, \text { cu }}$ for breaking wave conditions and not for non-breaking conditions. The corresponding graphs are given below for the 1:3 and the 1:6 sloped dike (Figure 15 and 16). The filled data points are results considering the absolute wave period $T_{a b s, m-1,0}$. The non-filled data points are determined by using the relative wave period $\mathrm{T}_{\text {rel,m-1,0. The influence factor decreases }}$ for positive angles of wave attack. For negative angles of wave attack the relative wave periods become smaller. Consequently the influence factors increase to high values and can not be used for describing the influence of current.

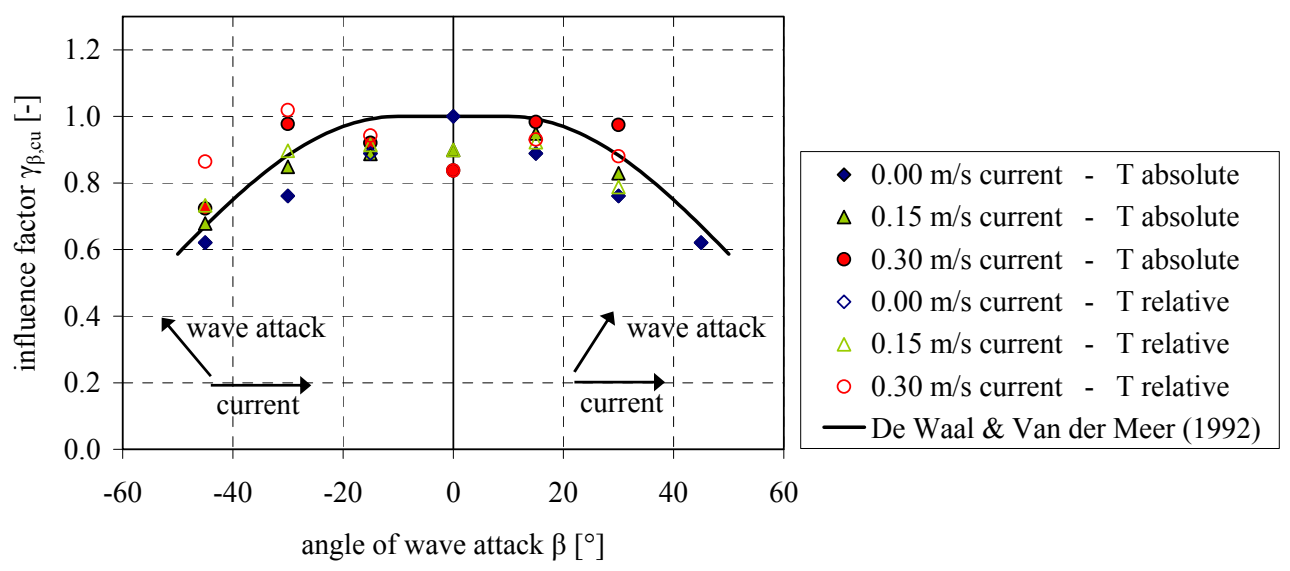

Figure 15. Current influence on wave overtopping including the relative wave period, 1:3 dike, br. waves 


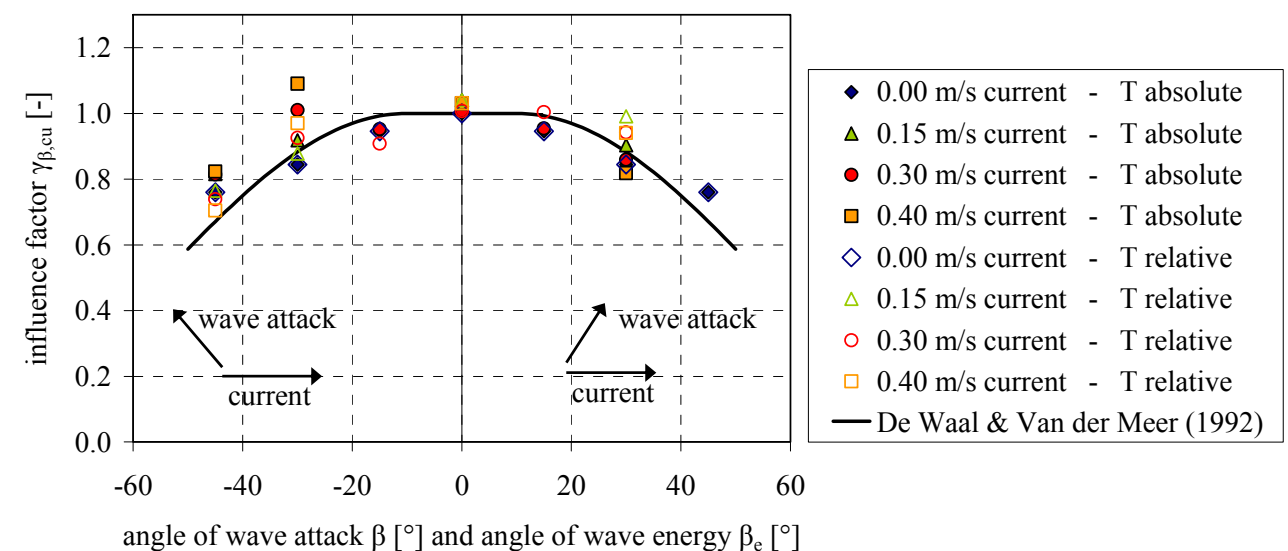

Figure 16. Current influence on wave overtopping including the relative wave period, 1:6 dike, br. waves

In the following, the theory of the wave energy direction is applied to the test results in Figure 17 to 19 for the 1:3 and 1:6 sloped dike for breaking and non-breaking (only 1:3 dike) waves. The filled data points are plotted against the angle of wave attack $\beta$ whereas the non-filled data points are plotted against the angle of wave energy $\beta_{\mathrm{e}}$. The data using the direction of wave energy are arranged further to the right than the data points that consider only the wave direction and not its energy direction and correspond fairly well to the graph of De Waal \& Van der Meer (1992).

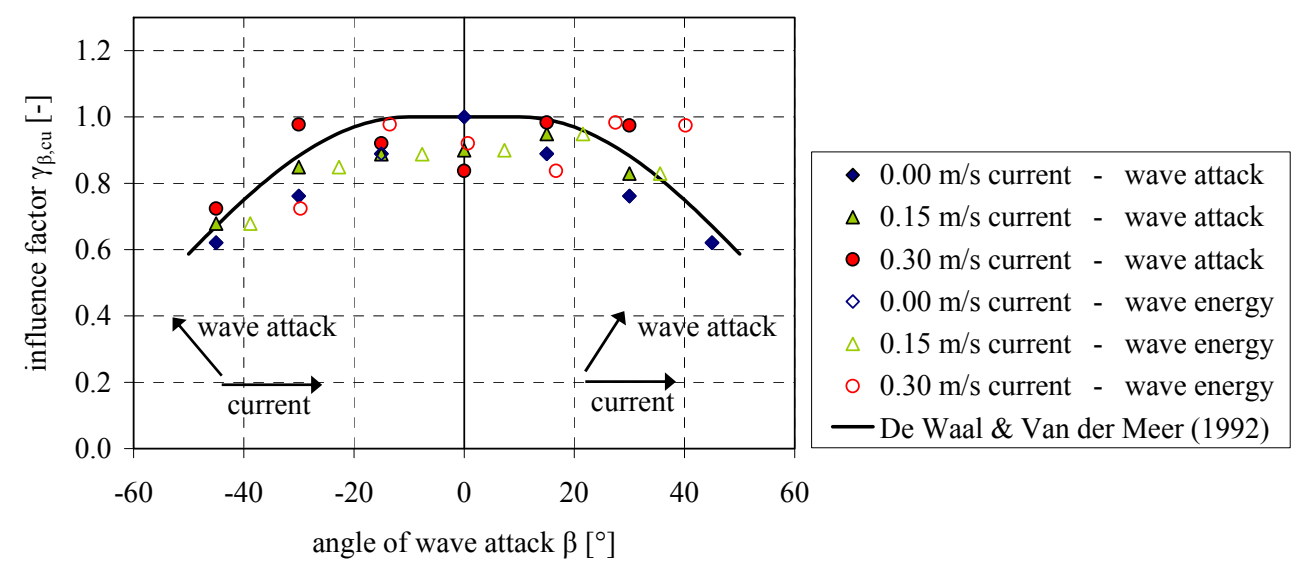

Figure 17. Current influence on wave overtopping including the angle of wave energy, 1:3 dike, br. waves

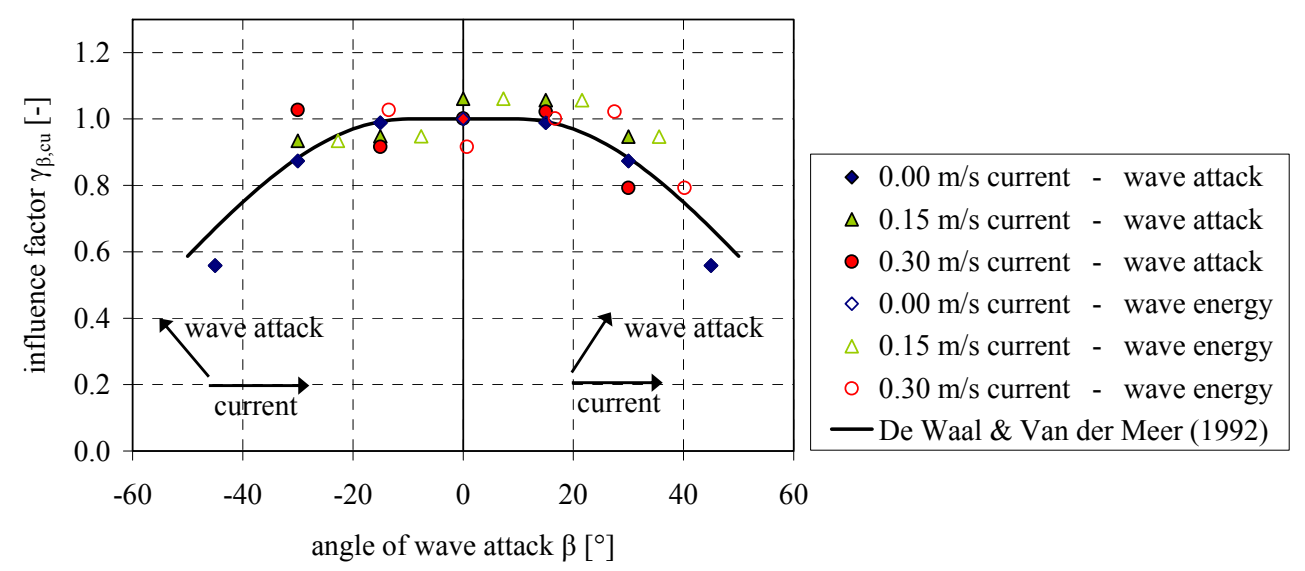

Figure 18. Current influence on wave overtopping incl. the angle of wave energy, 1:3 dike, non-br. waves 


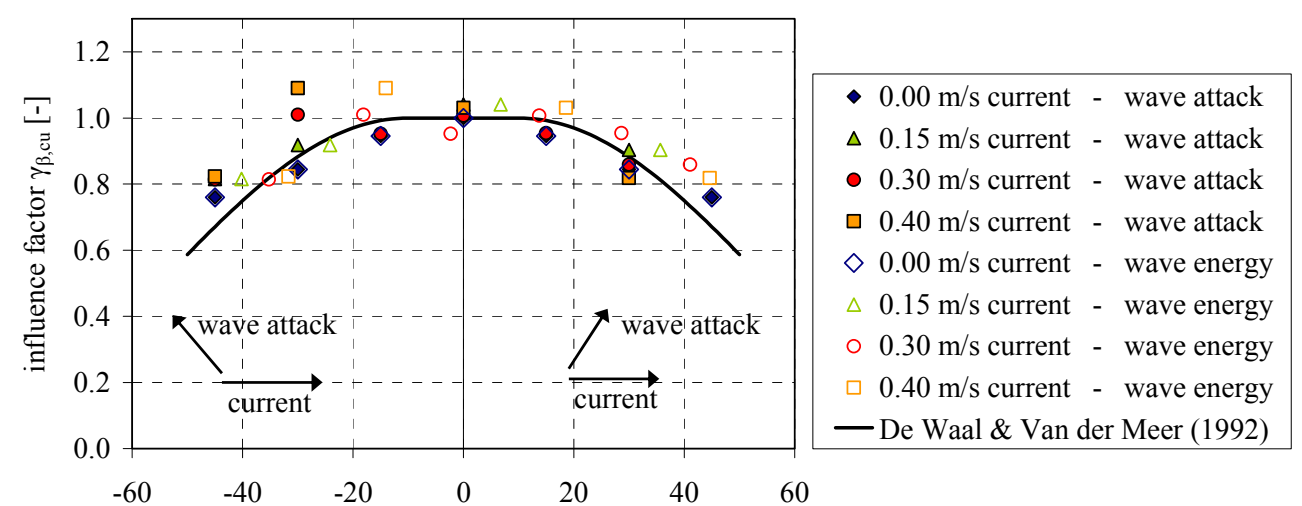

angle of wave attack $\beta\left[^{\circ}\right]$ and angle of wave energy $\beta_{\mathrm{e}}\left[^{\circ}\right]$

Figure 19. Current influence on wave overtopping including the angle of wave energy, 1:6 dike, br. waves

\section{CONCLUSION AND RECOMMENDATIONS}

The influence of current combined with different angles of wave attack on wave run-up and wave overtopping has been studied experimentally. The experimental study included two smooth dike slopes (1:3 and 1:6) and six different wave parameters. Oblique wave attack and current velocities parallel to the dike line have been combined in different test configurations.

The results for oblique and non-oblique wave attack agree well with the formula given by De Waal and Van der Meer (1992). The consideration of current along the dike line combined with normal wave attack leads to decreasing average wave run-up heights and overtopping-rates.

For wave overtopping the combination of oblique wave attack and current parallel to the dike was analysed by determine an influence factor $\gamma_{\beta, \mathrm{cu}}$. Using therefore the relative wave period $\mathrm{T}_{\text {rel, } \mathrm{m}-1,0}$ instead of the absolute wave period $\mathrm{T}_{\mathrm{abs}, \mathrm{m}-1,0}$ leads to rather high values and does not account the current influence on wave overtopping. Instead of that the influence-factor $\gamma_{\beta, \text { cu }}$ can be determined by using the angle of wave energy $\beta_{\mathrm{e}}$ instead of the angle of wave attack $\beta$.

In upcoming studies the influence of currentom wave run-up and wave overtopping will be investigated in ore detail. In addition the wave behaviour on the dike crest by analysing single wave events has to be determined as well as the flow processes on the dike crest in the presence of current and oblique waves.

\section{ACKNOWLEDGMENT}

The first part of the results was obtained from model tests carried out within the EU-Hydralabproject FlowDike (contract no. 022441), which enable researchers from different countries to use large scale facilities in Europe. The FlowDike-project has been a cooperation of three German Universities (RWTH Aachen University, TU-Dresden and TU-Braunschweig), the Czech Brno University of Technology, the University of Valencia (Spain) and VanderMeer Consulting B.V.. The second part of the results was obtained within a project supported by the German Ministry of Education and Research (BMBF) within the research project FlowDike-D and is a cooperation of RWTH Aachen University (reference number: 03KIS075), TU-Dresden (reference number: 03KIS076) and VanderMeer Consulting B.V..

Both test phases were combined within the project FlowDike-D. Rijkswaterstaat funded in both project phases some additional tests to complete the dataset with important test configurations.

\section{REFERENCES}

Ahrens, J.P. 1981: Irregular wave runup on smooth slopes. Coastal Engineering Technical Aid No. 8117. U.S.Army Corps of Engineers. CERC, Ft. Belvoir, Va. 22060.

De Waal, J. P., Van der Meer, J. W. 1992: Wave run-up and overtopping on coastal structures. Proceedings of the 23th International Conference on Coastal Engineering. pp. 1758-1771. Venice, Italy.

EurOtop-Manual. 2007: European Overtopping Manual, www.overtopping-manual.com. Eds Pullen, T., Allsop, N.W.H., Bruce, T., Kortenhaus, A, Schüttrumpf, H., Van der Meer, J.W.. Heide, Germany.

Hedges, T. S. 1987: Combinations of waves and currents: an introduction. Proceedings of Institution of Civil Engineers 82, pp. 567-585. 
Holthuijsen, L. H. 2007: Waves in oceanic and coastal waters. Cambridge Univ. Press. U. Kingdom.

Hughes, S.A. 2003: Estimating irregular wave runup on smooth, impermeable slopes. U.S. Army Engineer Research and Development Center. Vicksburg, MS, United States.

Hunt, I.A. 1959. Design of seawalls and breakwaters. Proceedings ASCE Journal of waterways, harbor and coastal engineering division. Volume 85. pp. 123 ff. Galveston, U.S.

Ohle, N., Möller, J., Schüttrumpf, H., Daemrich, K.-F., Oumeraci, H., Zimmermann, C. 2002: The influence of refraction and shoaling on wave run-up under oblique waves. Proceedings of the 28th International Conference Coastal Engineering. pp. 885-894. Cardiff, U.K.

Oumeraci, H., Schüttrumpf, H., Möller, J., Zimmermann, C., Daemrich, K.-F., Ohle, N. 2001: Influence of oblique wave attack on wave run-up and wave overtopping - 3D Model Tests at NRC/Canada with long and short crested waves- . Hannover, Germany.

Pohl, R., Heyer, T. 2005: Der Auflauf unregelmäßiger Wellen im Übergangsbereich zwischen Branden und Schwingen. Wasser und Abfall. pp. 34 - 38. Germany.

Schüttrumpf, H., Oumeraci, H. 2005: Layer thicknesses and velocities of wave overtopping flow at seadikes. Coastal Engineering. Vol. 52, Issue: 6, pp. 473-495. Amsterdam, The Netherlands.

Tautenhain, E., Kohlhase, S., Partenscky, H. W. 1982: Wave run-up at sea dikes under oblique wave approach. Proceedings of the 18th International Conference on Coastal Engineering. pp. 804-810. Cape Town, South Africa.

Treloar, P.D. 1986: Spectral wave refraction under the influence of depth and current. Coastal Engineering 9. pp. 439-452. Amsterdam, The Netherlands.

Van der Meer, J.W., Janssen, J. 1995. Wave run-up and wave overtopping at dikes. Wave forces on Inclined and vertical wall structures. pp. 1-27. New York, United States.

Van der Meer, J.W. 2010. Hydralab - FlowDike. Influence of current on wave run-up and wave overtopping, Detailed analysis on the influence of current on wave overtopping. Project Report vdm08310, version 1.0. Van der Meer Consulting. The Netherlands (unpubl. - subm. to the EU).

Wagner, H. 1968: Kennzeichnung der Wellenauflaufhöhe an geraden, glatten, undurchlässigen Böschungen im brandenden Bereich. Wasserwirtschaft Wassertechnik. Volume 18.

Wagner, H., Bürger, W. 1973. Kennwerte zur Seedeichbemessung. Wasserwirtschaft Wassertechnik (WWT). Volume 23. Issue 6. pp. 204-207.

Wassing, F. 1957: Model investigations of wave run-up carried out in the Netherlands during the last twenty years. Proceedings of the 6th International Conference on Coastal Engineering. Gainsville, Florida. 